\title{
BEHAVIOUR OF HUMANS AND BEHAVIOUR OF MODELS IN DYNAMIC SPACE
}

\author{
Peter NijKAmp \\ Department of Spatial Economics, Free University, Amsterdam, The Netherlands \\ Manuscript received: January 24, 2011 \\ Revised version: May 12, 2012
}

\begin{abstract}
NiJKAMP P., Behaviour of humans and behaviour of models in dynamic space. Quaestiones Geographicae 31(2), Bogucki Wydawnictwo Naukowe, Poznań 2012, pp. 7-19. 1 table, 1 fig. DOI 10.2478/v10117-012-0013-9, ISSN 0137-477X.
\end{abstract}

AbSTRACt. This paper addresses new trends in quantitative geography research. Modern social science research - including economic and social geography - has in the past decades shown an increasing interest in microoriented behaviour of actors. This is inter alia clearly reflected in spatial interaction models (SIMs), where discrete choice approaches have assumed a powerful position. This paper aims to provide in particular a concise review of micro-based research, with the aim to review the potential - but also the caveats - of micro-models to map out human behaviour. In particular, attention will be devoted to interactive learning principles that shape individual decisions. Lessons from cognitive sciences will be put forward and illustrated, amongst others on the basis of computational neural networks or spatial econometric approaches. The methodology of deductive reasoning under conditions of large data bases in studying human mobility will be questioned as well. In this context more extensive attention is given to ceteris paribus conditions and evolutionary thinking.

KEY WORDS: quantitative geography, spatial econometrics, space-time geography, space-economy

Peter Nijkamp, Free University, Department of Spatial Economics, De Boelelaan 1105, 1081 HV Amsterdam, The Netherlands; e-mail: pnijkamp@feweb.vu.nl

\section{Prefatory remarks}

"As far as the laws of mathematics refer to reality, they are not certain, and as far as they are certain, they do not refer to reality". Albert Einstein

One of the most revolutionary developments in our age has been the rapid introduction of miniaturisation in all fields of industrial technology, e.g. in the use of materials, medical science, information and communication technology (ICT), particle physics, or chemistry. The search for small items or particles in the natural sciences was encouraged by a seminal and challenging article by Richard Feynman (1960) that caused a radical transformation in fundamental research in physics and chemistry. His scientific work laid the foundations of the emergence and rising popularity of nanotechnology, essentially characterised by the motto 'small is beautiful'. Not only is it possible nowadays to store an entire 'lab on a chip', but also to store more information on the 'head of a pin' than on a mainframe computer a few decades ago.

These new developments are possible thanks to interconnected technologies and interoperable information systems (see also Haining et al. 2010). Similar trends can be observed in research in behavioural sciences, such as experimental psychology, micro-economics, criminology, transportation science, and human geography. An example is spatial interaction modelling based on discrete choice analysis, such as logit or probit models. 
Modern ICT developments and advanced statistical storage and data mining techniques have led to a drastic re-orientation in applied research in the behavioural sciences, along two lines. First, we observe a clear emphasis on micro- (individual) data (e.g. panel and longitudinal studies, individual survey questionnaires, interconnected data bases). And next, we see the emergence of extensive data bases (for instance, permanent observation and monitoring of individual traffic behaviour), which far exceed the limited empirical information on human behaviour in the past. This trend towards a wealth of individual multiactor behavioural data calls for a more systemic approach in applied research, e.g. complexity analysis, agent-based modelling, evolutionary behavioural geography, and so forth (see also Bavaud \& Mager 2009).

From a methodological perspective, the unprecedented volumes of data in our age question the relevance of a nomothetic or deductive approach in behavioural research. The traditional research starts from a series of propositions and testable hypotheses, to be validated by (often limited) empirical data (through the use of econometric models or appropriate statistical techniques). But in modern behavioural research, data are sometimes so extremely rich and extensive that a consistent testing of theoretical concepts may become so cumbersome that Hempel's 'bridge principle' can hardly be met. A reverse methodological solution is nowadays becoming more popular and appropriate, namely 'letting the data speak for themselves' (data-instigated theory). Through statistical identification techniques it is then possible to trace hidden structures in large data sets, which may then form a basis for new theory development employing cognitive research approaches ('computational social sciences'; see Lazer et al. 2009). This implies, inter alia, more emphasis on heuristic or 'data-rich' and 'theory-free' statistical techniques, such as computational neural networks, genetic algorithms, or self-organising mapping procedures.

In the present paper we will address new research challenges in the area of spatial analysis and modelling. After an illustration of the use of micro GSM data in a space-time micro-context, we will offer some conceptual observations on new trends in quantitative research on nonlinear dynamic spaces. Next, we will address a cumbersome concept in spatial research, viz. the ceteris paribus condition in relation to spatial equilibria, and review its relevance in data-instigated research. We will then devote some attention to spatial complexity analysis, followed by a review of recent applications. In this context, spatial networks offer a great research field for investigating the structural patterns in complex and dynamic systems. In this vein we also address evolutionary thinking in geography, and finally, we draw some research conclusions.

\section{Illustration: Micro-electronic footprint data in space-time geography}

Geography has increasingly lost traces of a descriptive discipline on man-environment relationships. On the contrary, modern geography has increasingly turned into a data-handling scientific activity over the past decades. Transport geography offers a clear illustration of this trend. The methodology of data collection - and subsequent statistical analysis in spatial interaction modelling - has exhibited drastic changes over the years. Many flow models used in the transportation field (e.g. for commuting, shopping, recreation, freight transport) have traditionally used origin-destination (OD) data, either at an individual or at an aggregate level. Most of these models were based on gravity-type of approaches, which later on were often translated into spatial interaction models (SIMs). Well-known examples are entropy models and activity-based spatial models. All these approaches needed extensive data, obtained either from observed flows (e.g. manual counting, loop detection, cameras) or from (self-)reporting methods (e.g. mobility diaries, electronic devices, survey methods, or telephone interviews). The increase in large-scale data bases on the spatial behaviour of people (see Hägerstrand 1970) laid the foundations for the operational nature of modern geography.

The history of quantitative data analysis in geography spans already several decades. The need for a more appropriate behavioural underpinning of spatial interaction models led in the 1980s to the emergence and popularity of discrete utility (or choice) models, in particular multinomial 
logit and probit models, later on followed by conjoint analysis modelling. Such individually-based models were proved to be consistent with aggregate-oriented spatial interaction models and got widely accepted in the transport research community. They also turned out to be well suited to actor-based policy simulation experiments, for instance in the context of micro-simulation models and agent-based models. In this vein, modern geography increasingly exhibits the methodology of the natural sciences based on advanced statistical analysis and testable models (for a review, see Pagliara \& Timmermans 2009).

All such models were widely used for prediction purposes, evaluation experiments and policy analyses in the field of planning and transportation science, for example to trace the system-wide effects of road pricing on the behaviour of car drivers. With the advent and introduction of ICT, the computing capacity in quantitative research showed a dramatic increase, so also spatial dynamics could be captured in a statistically more satisfactory way. Complexity theory has in recent years offered a remarkable contribution to a better understanding of the sensitivity of the evolution of spatial systems to endogenous non-linear space-time behaviour. Space-time dynamics (e.g. in the cellular automata domain) has become an important ingredient of advanced transportation research and spatial analysis, and prompted a new departure, viz. the use of data mining methods for large data sets (see also Batty 2005). The current use of computational neural networks and genetic algorithms demonstrates convincingly the great potential of more sophisticated data collection techniques. The real essence of space as highlighted in Tobler's (1970) law ("All things in space are related to each other, but nearby things are more related than distant things") has been taken up in a new strand of literature addressing spatial - and spatio-temporal - autocorrelation, either as testing devices or as design mechanisms for spatial (dynamic) models (see also Tobler 2004). Cellular automata, spatial filtering techniques and self-organised mapping procedures ('Kohonen maps') for spatial interaction analysis have been a logical follow-up and complement to the above-mentioned trends (e.g. Arribas et al. 2010, Codd 1968, Couclelis
1997, Kohonen 2000, Kulkarni et al. 2002 and Patuelli et al. 2010).

In the recent years, we have witnessed an increasing popularity of location-based services (LBS) and data using various kinds of electronic identification systems, so that at an individual level (a traveller, a container, a truck, or a taxi) the geographic position of a unit can be traced with great precision. Many applications are available for purchase and free to cell-phone and other wireless-device users. For example, Japanese parents use location-based tracking devices to monitor the spatial movement of their kids. This new approach will certainly prompt many new applications in space-time geography.

An interesting source of individually-based information on the space-time position and behaviour of persons is in principle available from mobile (or cell) phone data, derived from the GSM network. The penetration rate of mobile phones is rapidly reaching a full saturation level in most OECD countries, so a system-wide coverage does in principle exist, almost in continuous space-time format. Such data - as very accurate representations of an individual space-time location - are in principle available with telephone operators. If such data - in an anonymous form could be made available to the research community, an unprecedented source of information on the space-time geography of individuals could be used in applied research (for an overview, see Steenbruggen et al. 2010).

It is noteworthy that this idea of a continuous space-time map at an individual scale was already put forward by the late Swedish geographer Torsten Hägerstrand in 1967. He introduced the 'space-time cylinder' and its related timespace model (Fig. 1) to offer a description of both individual space-time patterns and the resulting spatial interactions if many individuals were 'en route' at the same time and place, a situation caused by the universal limited supply of daily time resources. His work was regarded as a new perspective in social-behavioural geography, as it highlighted so clearly the essence of interaction and congestion phenomena in space (see Pred 1977). Three constraints appear to act on the daily mobility pattern of individuals, viz. capability constraints, coupling constraints, and authority constraints. It also laid the foundations for activi- 
ty-based transport geography, but, unfortunately, lack of data and of an appropriate technology to implement the framework often precluded a full operational application of his path-breaking ideas. Now with the potential availability of largescale continuous space-time information bases on spatial movements of individuals, a really interesting novel approach might be developed, which may have great implications for spatial modelling. Two such approaches can be found in the literature. The first incorporates elements of cognition by considering individuals' preferences via the theory of affordances proposed by Gibson (1979) (Raubal et al. 2004). Cognitive constraints, e.g., choice behaviour, were not given explicit attention in the original time-geography framework. These constraints can help personalise location-based services (LBS), making it possible to collect more detailed information about the choices individuals make, their likes and dislikes. The other adjusts the space-time prism concept to support interactions and activities between the physical and virtual spaces (Yu \& Shaw 2008). This approach would help model and understand how individuals allocate their space and time resources in the age of mobile computing, when a variety of activities and services can be carried out on the go.

In the literature, we can already see the first interesting applications of GSM data, e.g. in the study of the intensity of social networks (Eagle et al. 2009), the spatial distribution and concentration of tourists (Ahas et al. 2006), traffic speed and journey time (Bar-Gera 2007), individual mobility patterns in cities (Gonzales et al. 2008), or urban structure patterns (Reades et al. 2009). Interesting applications can also be found in the use of private or public spaces by individuals (e.g., Calabrese et al. 2001), the concentration of people in a city (e.g., Reades et al. 2009), the activity spaces of commuters (Ahas et al. 2006), non-recurrent mass events such as a pop festival (e.g., Reades et al. 2007), the entry of tourists into a certain area of attraction (e.g., Ahas et al. 2007, 2008), or the estimation of spatial friendship network structures (e.g., Eagle et al. 2009). Especially in the transport sector, the potential applications are vast, and consequently, the use of cell-phone data has shown a rapid increase in urban transport applications. These data are a rich source of

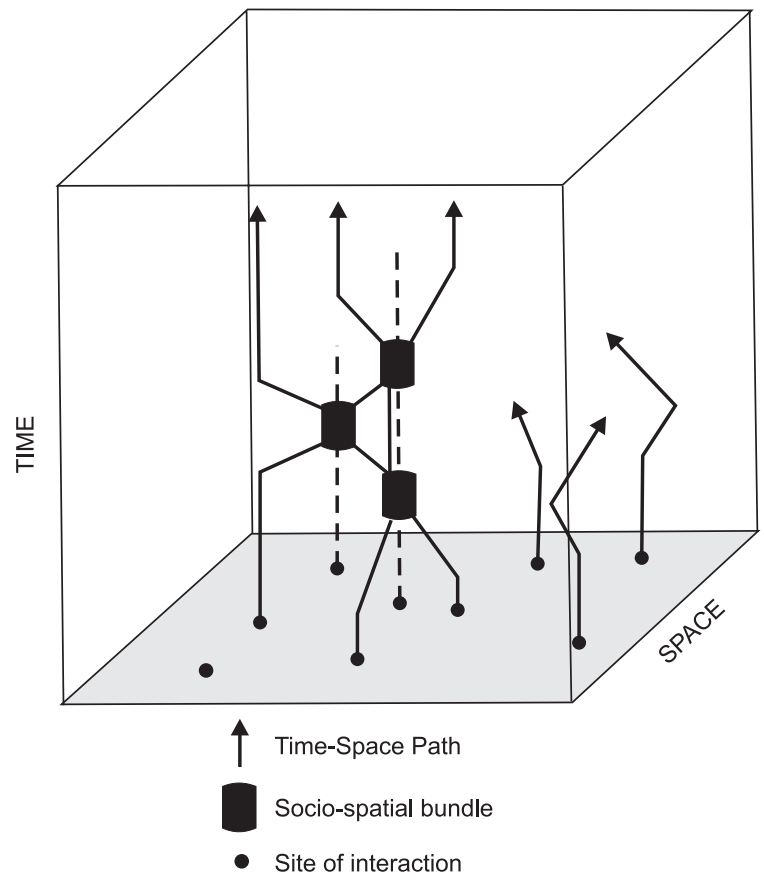

Fig. 1. Hägerstrand's time-space model Source: Warf (2006).

information on continuous space-time geography in urban areas. They can be used for daily traffic management, but also for incidence management, for instance, in case of big fatalities, terrorist attacks, or mass social events, such as festivals or demonstrations.

It should be noted that the use of LBS data (either GPS or GSM information) has also met with scepticism and even criticism, as in this case it may be possible to track humans in all their spacetime movements. Some authors even talk about 'geoslavery' ${ }^{1}$ as a new form of big-brother control on location behaviour (e.g., Dobson \& Fisher 2003) and highlight important privacy issues (Sui

1 Geoslavery is defined in the Encyclopedia of Human Geography (p. 186) as follows: "Geoslavery is a radically new form of human bondage characterized by location control via electronic tracking devices. Formally, it is defined as a practice in which one entity (the master) coercively or surreptitiously monitors and exerts control over the physical location of another individual (the slave). Inherent in this concept is the potential for a master to routinely control time, location, speed, and direction for each and every movement of the slave or, indeed, of many slaves simultaneously. Enhanced surveillance and control may be attained through complementary monitoring of functional indicators such as body temperature, heart rate, and perspiration". 
2004, Jiang \& Yao 2006). Notwithstanding such socio-ethical issues, GIS technology offers an important vehicle for the use of such geo-based devices for mobility planning and management. The Open GIS Consortium (OGC) (http:/ / www. opengis.org) through the OpenGIS Location Service (OPENLS) initiative has defined standards to facilitate the interaction with LBS. ESRI, the largest GIS company world-wide (Shiode et al. 2002), in its efforts to stay in the forefront of GIS technology has offered its services as part of the Amazon Cloud (ESRI 2010) (for a discussion on cloud computing for mobile users, see Kumar $\& \mathrm{Lu} 2010$ ). This will provide the organisation with the ability to run GIS services in the cloud without having to purchase the software. This in turn will offer LBS additional functionalities previously unavailable that can manipulate and analyse the spatial data, giving even more importance to the development of new approaches in the field of time-geography.

Modern GIS technology in combination with location-based services (LBS) - in the context of either GPS or GSM systems - is indeed able to design real-time tracking and tracing systems for goods and people. Especially the integration of spatial integration and individual information from various sources has raised public concern about personal surveillance and information privacy. As mentioned above, in principle, an integrated space-time information system may pave the road towards permanent location control, coined geoslavery (Dobson \& Fisher 2003, Goss 1995). Clearly, the advantages of remote-control tracking and tracing systems are numerous, for instance, in route navigation systems, LBS in the trucking sector, wristbands for tracking the movements of schoolchildren, incident identification among mountaineers, spatial positioning of temporarily released prisoners, etc. However, there are evidently also shadow sides to be faced by public authorities and commercial vendors or marketers aiming at exploiting the potential of such electronic information systems, in particular as an 'information master' may structurally control time, location, speed and direction for every movement of any individual. It is clear that specific regulations on the use of and access to such electronic tracking and controlling systems are needed to prevent any abuse and violation of privacy protection.
The previous observations offer a clear demonstration of the radical changes in modern geographical research, where large micro-data bases offer an unprecedented scope for detailed spatial analysis of human behaviour. This new opportunity calls also for a more critical reflection on the research methodology of geography. The latter issues will be touched upon in the next section, which is more explicitly devoted to the spatial footprints of GSM networks.

\section{Organising principles for the space- economy: A conceptual overview}

The research domain of modern geography is vast and increasingly interacting with other disciplines, such as economics, law, planning, political science, sociology, and architecture. This trend has caused important interdisciplinary cross-fertilisation and has also prompted a rapid introduction of advanced research tools, such as dynamic systems models, computable spatial economic equilibrium models (for instance, in new economic geography), spatial interaction analysis, discrete choice models, spatial network analysis, spatial innovation and diffusion analysis, migration studies, and so forth. Modern data mining techniques are important vehicles in this context.

Another set of important statistical tools that have been developed in the past decades is offered by spatial econometrics, which has gained much popularity in recent quantitative regional and urban research. Spatial econometrics has already a long history. It started as a simple statistical test to detect spatial autocorrelation (or spatio-temporal autocorrelation) in a multi-regional data set by using Moran's statistic. Later on, it was realised that the use of spatially correlated data in multi-regional models might lead to biased estimators (see Anselin \& Rey 2010). Two pathways were essentially developed to cope with autocorrelation in spatial models with interaction effects, viz. the spatial lag model and the spatial error model. The first class includes a spatially lagged dependent variable, while the second class contains a spatial auto-regressive error term expression. Spatial econometrics has gained a great deal of popularity in modern quantitative 
geographical research and has become a standard tool in this field. Over the years, much progress has been made by combining a spatially lagged dependent variable and a spatially autocorrelated error term in one model, while more recently also combined spatially lagged dependent and explanatory variables have been developed (the spatial Durbin model) (LeSage \& Pace 2009; Elhorst 2010).

A major limitation in current spatial econometric research - and a great future research challenge - is the fact that the determination of the spatial weight matrix is still fraught with many uncertainties. Essentially, the way a spatial weight matrix $W$ is normally estimated (e.g., via the reverse distance between adjacent regions, the length of the common border between contiguous areas) is rather naive and does not incorporate any cognitive information on the interaction intensity among regions, such as socio-cultural cohesion, behavioural commonalities, interlinked institutional regimes. There is, no doubt, much scope for further sophisticated research by endogenising the specification of the $W$ matrix. In this context, adjusted techniques - based on e.g. instrumental variables methods - may have to be employed. Similar observations can be made on space-time autocorrelation, where the combined lag structure - over space and time - needs more careful attention.

It should be noted that one issue has received less attention in quantitative applied research, namely the management of geographical space (e.g. sustainable land use planning), which has assumed a far less prominent place in spatial statistics and modelling, although the current popularity of complex and self-organising systems is a promising new departure (see Portugali 2006). The planning of space (e.g. land use, infrastructure) has in recent years been positioned in an evolutionary world, which is less dictated by top-down control, but much more by micro-behaviour from a bottom-up perspective in which learning and interaction play a crucial role. The development of spatial mega data systems ties in with these new trends in planning, which has increasingly moved into coordination of spatial developments over the past years rather than the command and control of spatial developments (see Portugali 2000).
Clearly, the existence of spatial externalities (e.g. density effects, environmental decay) will always prompt a call for intervention, but in recent years the nature of this intervention shows a tendency towards a conviction rather that a coercion mode. In the recent literature we observe an increasing popularity of self-organising principles for dynamic interactive spatial systems. This runs parallel to the rising acceptance and use of spatial complexity concepts (see also Section 5), which are essentially based on nonlinear, dynamic interaction effects among agents in space. Such effects are usually characterised by a multi-disciplinary and multi-actor constellation, with various feedback and learning effects. Consequently, spatial governance systems have been re-modelled into game-like negotiation strategies in which public actors have become an endogenous part of a broader policy system.

Despite the changing nature of planning principles and practice, there is still the need for efficient and effective ordering principles. In his seminal article on "The architecture of complexity", Simon (1962) makes an original attempt to formulate some general organising principles for systems subject to systemic complexity. His governance rules are essentially based on three anchor points: the existence of a rationally bounded paradigm, the adoption of learning principles, and the use of decomposed hierarchical principles favouring management efficiency. This approach is essentially an attempt to reduce complexity to 'simplexity'.

From an analytical perspective (see Reggiani \& Nijkamp 2009), a wealth of concepts and models has been developed over the past two decades, in particular: bifurcation, chaos, synergetics, resilience, complex networks, evolutionary behaviour, scale-free networks, criticality, or small-world networks. Many of these models are purely illustrative and pedagogical in nature, but in recent years we have witnessed various interesting applications, for example in traffic management, ecosystems policy, ethnic conflict management, medical treatment and therapy, financial crisis management, innovation policy, and urban evolutionary development.

Such new analytical departures originate from well-known and solid frameworks, such as gravity theory, entropy modelling, neural network 
analysis, genetic algorithm applications, Thuring principles, power laws, preferential attachment principles, etc. It is noteworthy that in their spatial manifestation, many of these principles are directly or indirectly rooted in Tobler's first law (which is essentially a consequence of the gravity principle).

It is important to note that many of the abovementioned modelling types are rather general natural science tools - and not necessarily specific behavioural analysis tools, so that the question may be raised of whether such models are relevant and appropriate research tools in analysing the space-economy. The use of the methodology of 'social physics' presupposes the fulfilment of two conditions: (i) a formal correspondence between relevant social science and natural science phenomena; and (ii) a substantive behavioural interpretation of 'social physics' models, so that behavioural motives can be traced in such models. It is important to mention here that in many cases these two conditions are met (for example, entropy models are essentially generalised cost minimisation models), so there is hardly a valid counter-argument to find for the use of social physics models in geography.

Clearly, social physics is a translational research approach in which findings from one discipline are incorporated into the research design in another discipline. But this is only a partial strategy to study real-world phenomena from a perspective of multiple disciplines. The challenge of interdisciplinary research essentially boils down to a methodological issue of the demarcation lines and bridges between distinct disciplines. This will be further outlined in the next section.

\section{Ceteris paribus in the modern space- economy}

In its long history, social science theory and application has adopted a consistent, though rather restrictive, methodological approach in dealing with the presence of multiple disciplines by drawing strict border lines and assuming developments in a different disciplinary domain as given. For example, location analysis in economic geography took for granted that psycho- logical perception and preference formations were handled by psychologists, while the results of individual preferences were assumed by the economic geographer to be given, without him asking whether there might be feedback effects through which geographical space might impact on preference formation or spatial attitudes. The simplifying and stylised assumption in such a reductionist approach increased the consistency but not necessarily the realism in regional and urban research (see also Nijkamp 2007).

Such a reductionist assumption originates essentially from a ceteris paribus condition which has been introduced in social science research to handle system-internal (endogenous) and systemexternal (exogenous) factors in a consistent way. The focus on a few selected variables in a research design leads of course to a streamlined approach, although this is not strictly needed from a conceptual or logical perspective (Nijkamp 2007). In real-world applications, this approach may even frustrate transferability of scientific findings to other empirical domains. Admittedly, the ceteris paribus condition forces the research to concentrate on the main factors to be studied, so that - in a partial sense - strict inferences can be drawn. Interestingly enough, the ceteris paribus has already a long history; according to Persky (1990), its earliest use in the current meaning dates back to the year 1311(!) when it was already used in scholastic philosophy. The ceteris paribus postulate was introduced as a major analytical tool in economic equilibrium analysis since the seminal work of Marshall (1898), who needed a demarcation of his economic research domain in order to guarantee a partial equilibrium. Even though general equilibrium theory was able to relax the ceteris paribus assumptions, the necessity to introduce stylised assumptions was never questioned, not even in spatial equilibrium theory, general systems analysis, and computable general equilibrium theory.

With the advent of dynamic and complex systems, the issue of the demarcation of disciplines and research domains has seen a revival. For example, if we make a distinction between fast and slow dynamics in space (e.g. fluctuating daily traffic flows versus the construction of transport infrastructure), it is questionable which factors have to be regarded as constant in the same 
model. Clearly, as Kaldor (1985) has argued in his Okun Memorial lecture, it is difficult to imagine economics without equilibrium; the ceteris paribus is a postulate that is critical in standard economic equilibrium thinking. Kaldor then continues: "It seems clear that if we are to get out of the present impasse we must begin by constructing a different kind of abstract model, one that recognizes from the beginning that time is a continuing and irreversible process; that it is impossible to assume the constancy of anything over time, such as the supply of labour or capital, the psychological preferences for commodities, the nature and number of commodities, or technical knowledge" (Kaldor 1985: 61).

New methodological departures may perhaps circumnavigate the strict limitations of a ceteris paribus approach, such as the analysis of dissipative spatial structures, complexity theory, evolutionary approaches, or the use of cognitive (or learning) principles. An interesting challenge is offered by the above-mentioned trend towards data-driven research in which spatial econometrics and spatial filtering approaches may relax the limitations of a strict ceteris paribus postulate. These issues certainly prompt a new debate on specification theory in behavioural spatial research.

The ceteris paribus condition has been the crucial element in equilibrium theory, as this is the only tool to identify the conditions under which a space-economy is in balance. However, with the increasing availability of large data sets (and with the emergence of advanced data mining techniques), the specification of spatial equilibrium models - with a large share of ceteris paribus conditions - is becoming less relevant, as such an extensive data set may contain a multiplicity of ceteris paribus variables. Consequently, the specification of spatially autocorrelated models becomes more problematic, so it seems plausible that exploratory spatial autocorrelation modes will gain more importance in the future.

Next, there is another trend in ceteris paribus research, namely controlled experimentation through so-called CP networks. In this way, microinformation on user preferences can be handled in the context of automated decision making on the basis of ceteris paribus interpretations (see, e.g., Boutilier et al. 2004, McGeachie \& Doyle 2002).
Finally, ceteris paribus also plays a role in counterfactual analysis, which aims to trace alternative developments under 'what if' or 'what if not' conditions. A good example can be found in a recent study on the efficiency of the Victorian British Railway Networks by Casson (2009). Also here, the spatial interaction component plays a critical role.

\section{Spatial-economic complexity}

"I truly believe that we are at the threshold of understanding complexity."

(...)

"The real reason is the data: when it comes to our social and economic systems, we can increasingly monitor what is going on. We can trace where people are, when and with whom they communicate, we can track shopping and travel patterns, and so on. To be sure, these penetrating technologies raise fundamental questions about privacy." (...)

"Much of our previous work in complexity was driven by theory, by ideas that were not always well rooted in reality. On the back of network theory a new, quite pragmatic approach to complexity is emerging: one which is driven by data and by measurements, and which leads to theories that are motivated by a deep desire to understand what is really going on. This data-rich era is creating an unprecedented opportunity, and all we need is the right attitude to crack the mysteries of complex systems."

(Barabási 2009: 26)

Complexity has turned into a fashionable concept in contemporaneous dynamic research. Complexity refers to an organised structure that is driven by multi-actor interactions at various scale levels where selection and learning play a key role. They lead to nonlinear systemic feedback effects that, through path dependency and fast and slow nonlinear dynamics, create the conditions for unexpected developmental trajectories of a system (Reggiani \& Nijkamp 2009). It is not a surprise that complexity research is often linked to resilience, sustainability, Volterra-Lotka and predator-prey dynamics, symbiosis and self-organisation. Complexity forms a contrast with traditional reductionism, as in a complex 
system the macro-behaviour of a system cannot be unambiguously understood from the emergent properties of the constituent elements that may have self-organising local interactions. This interaction at various scale levels implies that complex systems are closely related to dynamic networks. It goes without saying that complex systems prompt various serious questions about the predictability of such systems, the relation between emergent properties and micro-interactions, the origin and nature of self-organisation and learning, the stochasticity in complex models, the simplicity-simplexity-complexity chain, and the econometrics of such models.

Usually, complex systems have a multiplicity of interacting elements or modules, so graph theory may be an appropriate analytical tool in the study of complex systems. Mobility, airline connections or Hägerstrand's space-time geography provide illuminating examples of complex networks.

The research on the behaviour of networks started with the introduction of random graphs in which network nodes were randomly connected by links (see Erdős \& Rényi 1959). A drawback of this approach was that such networks displayed a highly regular structure, which forms a contradiction with real-world phenomena where unequal distributions and concentrations are likely to appear.

A new perspective was offered by the introduction of small-world networks by Watts \& Strogatz (1998), who designed a simple network on a ring in which each node was only linked to its nearest neighbours. These networks, coined small-world networks, offered a broad spectrum of organised and random patterns.

Almost simultaneously, Barabási \& Albert (1999) provided a new extension by introducing the principle of preferential attachment through which an extension of a network by the addition of a node could be analysed. Preferential attachment means essentially that a new node seeks for connectivity with an existing node that is wellconnected to the rest of the network, so that distance friction costs to other nodes are minimal. In this framework, the so-called scale-free networks were introduced. Such networks may have a relevance for hub-and-spoke systems in the airline sector (see Reggiani \& Nijkamp 2010) or for social networks (see Boccaletti et al. 2006). The degree distributions can be related to a power law, as this distribution describes a structure with a high connectivity for a few central places (hubs) in the network and a low connectivity for other nodes. The hubs have of course sensitive positions in a scale-free network, at least in the case of drastic changes.

In geography, research on complex spatial systems has in recent years shown a rapid rise in scientific interest. Applications include inter alia:

- morphogenesis of cities (Batty 2005, Medda et al. 2009);

- configuration of airline networks (Reggiani \& Nijkamp 2010);

- urban evolution (Wilson 2009, Rozenblat \& Melançon 2009);

- geography of internet infrastructure (Tranos 2005);

- dynamics in residential locations (Fotheringham et al. 2002);

- complex urban and regional systems (Bertuglia \& Vaio 2009; Portugali 2004, 2008);

- urban networks dynamics (Andersson et al. 2006); and

- small spatial networks (Gorman \& Kulkarni 2004).

In conclusion, complexity theory offers an entirely new reason for quantitative dynamic research in geography. The main challenge for the years ahead will be the operational development of testable models that can stand the scrutiny of the real world.

Next to complexity models, in the recent years we have also witnessed the emergence of another, related strand of literature, namely evolutionary thinking in geography. This will be briefly discussed in the next section.

\section{Evolutionary thinking in geography}

$$
\begin{array}{r}
\text { "Darwinism is too important } \\
\text { to be left to the biologists." } \\
\text { (J. Mokyr) }
\end{array}
$$

Evolutionary thinking has gradually entered the domain of the social sciences, be it with some hesitation and criticism (see, e.g., Gough et al. 2008). In some disciplines, such as economics (see 
Nelson \& Winter 1982), it has gained a respectable position, but in other disciplines it is still at the beginning of its life cycle. A field where evolutionary thinking has been widely adopted is ecological economics (see Boulding 1981, Georgescu-Roegen 1971, Penn 2003, van den Bergh 2007, van den Bergh et al. 2007). Penn offers an interesting evolutionary-oriented explanation of "why humans are ecologically destructive, overpopulate, overconsume, exhaust common pool resources, discount the future, and respond maladaptively to modern environmental hazards" (2003: 1). In his view, instigated by evolutionary thinking, human-based environmental decay originates from a poor adaptability of the human species to its environment. It is clear that the rational decision-making paradigm based on selfish agents and oriented towards short-term utility is not compatible with long-term sustainable development. In a recent article, van den Bergh (2007) offers an insightful overview of the distinct features of evolutionary, ecological, and mainstream environmental and resource economics (see Table 1).

Evolutionary thinking also questions the relevance of per capita GDP as a relevant and reliable growth indicator (or an indicator of social welfare). An alternative way of conceiving welfare growth is to introduce the notion of evolutionary growth, which may comprise concepts like: increasing diversity, increasing complexity, extended division of labour, new ways of transmitting information, population growth, or adaptation (see van den Bergh 2007).
It should be noted that many evolutionary contributions to social science are not based on hard-core Darwinism but rather on interpretative or symbolic similarities to Darwinism using metaphors from evolution theory. For instance, in geography, scholars talk more about evolutionary thinking in geography than about evolutionary geography. In the same vein, evolutionary modelling is often an adjustment of standard dynamic modelling with a few symbolic components prompted by evolutionary thinking. An interesting contribution to the debate on evolutionary modelling can be found in a recent study by Safarzynska (2010), who made a successful attempt to design a series of cornerstones of evolutionary models in ecological economics. She mentions the following ingredients as necessary conditions:

- diversity;

- innovation and selection;

- bounded rationality;

- diffusion;

- path dependency and lock-in;

- co-evolution;

- multilevel and group selection; and

- indigenous growth mechanisms.

In her study she shows that advanced evolutionary modelling techniques may mean a particularly important and applied breakthrough in the following research domains:

- evolutionary game theory and selection dynamics;

- evolutionary computation; and

- multi-agent modelling.

Table 1. Differences in emphasis between evolutionary, ecological and mainstream environmental and resource economics

\begin{tabular}{|c|c|c|}
\hline Evolutionary economics & Ecological economics & Environmental economics \\
\hline Evolutionary potential & Optimal scale & Optimal allocation \\
Agent, technique, and product & Riodiversity & Optimal R\&D \\
diversity & Opts \\
Innovation-recombination/ mutation & Divergent views on innovation & Efficiency, cost-effectiveness \\
Fitness & Equity (intra/intergenerational) & Sustainable macro growth \\
Evolutionary stability & Resilience & Growth of limits \\
Adaptive limits & Limits to growth & Economic irreversibility \\
Path-dependence & Ecological irreversibility & Short/medium run \\
Varying time scales & Medium/long run & Monetary indicators \\
Population/distribution indicators & Physical and biological indicators & Rational behaviour \\
Bounded rationality and selection & Myopic behaviour & Utilitarianism \\
Functional morality (fitness) & Environmental ethics & Equilibrium, comparative statics/ \\
Adaptive individuals and systems & Causal processes & dynamics \\
\hline
\end{tabular}

Source: adapted from van den Bergh (2004). 
It is noteworthy that there appears to be a striking parallel between evolutionary modelling and artificial intelligence, in particular in the following fields:

- computational neural networks (see, e.g., Fischer et al. 2010);

- self-organised criticality (see, e.g., Reggiani and Nijkamp 2009);

- adaptive learning models (see, e.g., Bertuglia and Vaio 2009); and

- self-organising mapping procedures (see, e.g., Kohonen 2000).

Applications of evolutionary approaches to geography are still rare, as it has taken some time before the discipline has adopted this new paradigm. One of the reasons is that at the same time, new economic geography has come into being (see Krugman 1991), which argues that the distribution of economic activity is the result of long-lasting agglomeration forces and inter-regional or international trade in an open economic system. New economic geography rather advocates universal economic motives related to rational decision-making, without paying attention to space specificity (or non-neutrality of space). Evolutionary approaches are more related to diversity, selection and real space, rather than universal behaviour, as this excludes adaptability of economic agents as well as lock-in situations. Examples of contributions to evolutionary thinking in geography can be found, inter alia, in Storper (1997), Boschma \& Lambooy (1999), Maggioni (2002), Brenner (2004), Boschma \& Frenken (2006), and Frenken (2007).

Over the past years the number of applications of evolutionary thinking in geography has extended. Examples can be found in:

- firm dynamics and entrepreneurship (Stam 2006);

- industrial dynamics (Boschma \& Frenken 2006);

- network analysis (Barabási \& Albert 1999);

- spatial systems' evolution (Boschma 2004);

- urban growth (Andersson et al. 2006);

- knowledge flows (Maggioni 2002); and

- spatial policy (Lambooy \& Boschma 2001).

These applications reveal interesting features, although most of them are based on simplified metaphors or evolutionary symbols rather than hardcore Darwinist modelling principles. As a consequence, there is still a range of research challenges in economic geography, in particular (i) a test of the operational validity of evolutionary approaches in the case of value transfer; (ii) specification of the micro-behavioural basis of a multiplicity of factors; (iii) a match between evolutionary behaviour and evolutionary modelling, including feedback and lock-in behaviour; and (iv) a design of long-range data bases in space-time evolutionary geography as a basis for advanced applied modelling.

\section{Prospect}

In modern space-time geography, including transport science, we will most likely see a trend towards massive micro-data sets on human mobility. This will prompt the need for smart spatial data management and for efficient statistical data manipulation where data mining and data kriging will play a central role.

The emergence of large data sets on spacetime movements of individuals will also lead to a need for systematic comparative study in which spatial meta-analysis of large data manipulations may play a central role.

And finally, there will be a need for better forecasting tools based on data-instigated theoretical frameworks. In space-time geography, this may also lead to challenging issues on evolutionary data-handling techniques.

\section{References}

Ahas R., Aasa A., Mark U., Pae T. \& Kull T., 2006. Seasonal tourism spaces in Estonia: Case study with mobile positioning data. Tourism Management, 28(3): 898-910.

Ahas R., Aasa A., Silm S. \& Tiru M., 2007. Mobile positioning data in tourism studies and monitoring: Case study in Tartu, Estonia. In: Sigala M., Mich L. \& Murphy J. (eds), Springer computer science: Information and communication technologies in tourism. Springer, Berlin: 119-128.

Ahas R., Saluveer E., Tiru M. \& Silm S., 2008. Mobile positioning based tourism monitoring system: Positium barometer. In: O'Connor P., Höpken W. \& Gretzel U. (eds), Information and communication technologies in tourism 2008. Springer, Berlin: 475-485.

Andersson C., Frenken K. \& Hellervik A., 2006. A complex networks approach to urban growth. Environment and Planning A, 38: 1941-1964.

Anselin L. \& Rey S.J. (eds), 2010. Perspectives on spatial data analysis. Springer Verlag, Berlin. 
Arribas D., Nijkamp P. \& Scholten H., 2010. Multidimensional urban sprawl in Europe: A self-organizing map approach. Technical report. Department of Spatial Economics, VU University, Amsterdam. Research Paper.

BAR-GERA H., 2007. Evaluation of a cellular phone-based system for measurements of traffic speeds and travel times: A case study from Israel. Transportation Research, Part C, 15(6): 380-391.

BARABÁSI A.L., 2009. We are at the threshold of understanding complexity. In: 12 Scientists on the 21st Century. World Science Forum, Budapest: 19-26.

BARABÁSI A.L. \& AlBERT R., 1999. Emergence of scaling in random networks. Science, 286: 509-512.

Batтy M., 2005. Cities and complexity. MIT Press, Cambridge, MA.

Bavaud F. \& Mager C. (eds), 2009. Handbook of theoretical and quantitative geography. UNIL, Lausanne.

BERGH J.C.J.M. vAN DEN, 2004. Optimal climate policy is a utopia: From quantitative to qualitative cost-benefit analysis. Ecological Economics, 48: 385-393.

BERGH J.C.J.M. VAN DEN, 2007. Evolutionary thinking in environmental economics. Journal of Evolutionary Economics, 17: 521-549.

Bergh J.C.J.M. van den, Faber A., Idenburg A.M. \& OOSTerhuis F.H., 2007. Evolutionary economics and environmental policy: Survival of the greenest. Edward Elgar, Cheltenham.

Bertuglia C.S. \& VAio F., 2009. The complexity approach to urban and regional systems and to the economy in general. Review of Economic Conditions in Italy, 2: 123-176.

Boccaletti S., Latora V., Moreno Y., Chavez M. \& Hwang D.U., 2006. Complex networks: Structures and dynamics. Physics Report, 424 (4-5): 175-308.

Boschma R.A., 2004. Competitiveness of regions from an evolutionary perspective. Regional Studies, 38(9): 1001-1014.

Boschma R.A. \& FrenKen K., 2006. Why is economic geography not an evolutionary science? Towards an evolutionary economic geography. Journal of Economic Geography, 6(3): 273-302.

Boschma R.A. \& Lambooy J.G., 1999. Evolutionary economics and economic geography. Journal of Evolutionary Economics, 9: 411-429.

Boulding K.E., 1981. Evolutionary economics. Sage Publications, Beverly Hills.

Boutilier C., Brafman R.I., Domshlak C., Hoos H.H. \& Poole D., 2004. CP-Nets: A tool for representing and reasoning with conditional ceteris paribus preference statements. Journal of Artificial Intelligence Research, 21: 135-141.

BRENNER T., 2004. Local industrial clusters - existence, emergence and evolution. Routledge, London and New York.

Calabrese F., Ratti C. \& Reades J., 2001. Eigenplaces: segmenting space through digital signatures. Pervasive Computing, 10: 1-6.

CASSON M., 2009. The efficiency of the Victorian British railway network: A counterfactual analysis. Networks and Spatial Economics, 9(3): 339-378.

CodD E., 1968. Cellular automata. Academic Press, New York.

Couclelis H., 1997. From cellular automata to urban models. Environment and Planning B, 24: 165-174.

Dobson J.E., FIsHer P.F., 2003. Geoslavery. IEEE Technology and Society Magazine, Spring: 47-52.

Eagle N., Pentland A. \& Lazer D., 2009. Inferring friendship network structure by using mobile phone data. PNAS, 9(36): 15274-15278.

ElHorst J.P., 2010. Applied spatial econometrics: Raising the bar. Spatial Economic Analysis, 5(1): 10-28.
ERDŐs P. \& RÉnYI A., 1959. On random graphs. Publicationes Mathematicae, 6: 290-297.

ESRI, 2010. ESRI press release. Retrieved from http: //www. esri.com/.

Feynman R., 1960. There is plenty of room at the bottom. Engineering and Science, 23(5): 22-36.

Fischer M.M., ReIsmann M. \& Scherngell T., 2010. Spatial interaction and spatial autocorrelation. In: Anselin L. \& Rey S.J. (eds), Perspectives on spatial data analysis. Springer-Verlag, Berlin: 61-82.

Fotheringham A.S., Brunsdon C. \& Charlton M., 2002. Geographically weighted regression. John Wiley, Chichester, UK.

FRENKEN K. (ed.), 2007. Applied evolutionary economics and economic geography. Edward Elgar, Cheltenham.

Georgescu-Roegen N., 1971. The entropy law and the economic process. Harvard University Press, Cambridge, MA.

GIBSON J., 1979. The ecological approach to visual perception. Houghton Mifflin, Boston MA.

Gonzalez M.C., Hidalgo C.A. \& Barabási A.L., 2008. Understanding individual human mobility patterns. Nature, 453: 779-782.

GoRMAN S.P. \& KULKARNI R., 2004. Spatial small worlds. Environment and Planning, B, 31(2): 273-296.

Goss J., 1995. We know who you are and we know where you live. Economic Geography, 71(2): 171-198.

Gough I., Runciman G., Mace R., Hodgson G. \& Rustin M., 2008. Darwinian evolutionary theory and the social sciences. 21st Century Society, 3(1): 65-86.

HäGERSTRAND T., 1970. What about people in regional science? Papers of the Regional Science Association, 24: 7-21.

Haining R.P., KerRy R. \& Oliver M.A., 2010. Geography, spatial data analysis and geostatistics: An overview. Geographical Analysis, 42(1): 7-31.

JIANG B. \& YAO X., 2006. Location-based services and GIS in perspective. Computers, Environment and Urban Systems, 30: 712-725.

KALDOR N., 1985. Economics without equilibrium. University College Cardiff Press, Cardiff.

KOHONEN T., 2000. Self-organising maps. Springer-Verlag, New York.

KRUGMAN P.R., 1991. Increasing returns and economic geography. Journal of Political Economy, 99(3): 483-499.

Kulkarni R., Schintler L.A., Stough R.R. \& Button K., 2002. A Kohonen self-organizing map approach to modeling growth pole dynamics. Networks and Spatial Economics, 2: 175-189.

KUMAR K. \& Lu Y., 2010. Cloud computing for mobile users: Can offloading computation save energy? Search, 43(4): $51-56$.

Lambooy J.G. \& Boschma R.A., 2001. Evolutionary economics and regional policy. Annals of Regional Science, 35: 113-131.

Lazer D., Pentland A., Adamic L., Aral S., Barabási A.L., Brewer D., Christakis N., Contractor N., Fowler J., Gutmann M., Jebara T., King G., Macy M., Roy D. \& Alstyne M. van, 2009. Computational social science. Science, 323: 721-724.

LeSAGE J.P. \& PACE R.K., 2009. Introduction to spatial econometrics. Taylor and Francis, Boca Raton.

MAGGioni M.A., 2002. Clustering dynamics and the location of high-tech firms. Springer, Heidelberg.

Marshall A., 1898. Principles of economics. MacMillan, London.

McGeachie M. \& Doyle J., 2002. Efficient utility functions for ceteris paribus preferences. American Association for Artificial Intelligence: 279-284. 
Medda F., Nijkamp P. \& Rietveld P., 2009. Dynamic effects of private costs on urban shape. In: Reggiani A. \& Nijkamp P. (eds), Complexity and spatial networks. Springer-Verlag, Berlin: 51-60.

NELSON R. \& WINTER S., 1982. An evolutionary theory of economic change. Harvard University Press, Cambridge, MA.

NIJKAMP P., 2007. Ceteris paribus, spatial complexity and spatial equilibrium - an interpretative perspective. Regional Science and Urban Economics, 37: 509-516.

Pagliara F. \& Timmermans H.J.P., 2009. Choice set generations in spatial contexts. In: Bavaud F. \& Mager C. (eds), Handbook of theoretical and quantitative geography. UNIL, Lausanne: 335-364.

Patuelli R., Griffith D.A., Tiefelsdorf M. \& NiJKamp P., 2010. Spatial filtering methods for tracing space-time developments in an open regional system. In: Frenckel A., McCann Ph. \& Nijkamp P. (eds), Societies in motion. Edward Elgar, Cheltenham (forthcoming).

PenN D.J., 2003. The evolutionary roots of our environmental problems: Towards a Darwinian ecology. The Quarterly Review of Biology, 78(3): 275-301.

PersKy J., 1990. Retrospectives: Ceteris paribus. Journal of Economic Perspectives, 4(2): 187-193.

Portugali J., 2000. Self-organization and the city. Springer-Verlag, Berlin.

PoRtUGAli J., 2004. Toward a cognitive approach to urban dynamics. Environment and Planning, B, 31: 598-613.

Portugali J. (ed.), 2006. Complex artificial environments. Springer-Verlag, Berlin.

Portugali J., 2008. Learning from paradoxes about predictions in self-organizing cities. Planning Theory, 7: 248262.

PRED A., 1977. The choreography of existence. Economic Geography, 53: 207-221.

Raubal M., Miller H. \& Bridwell S., 2004. User centered time geography for location-based services. Geografiska Annaler, B, 86(4): 245-265.

Reades J., Calabrese F. \& Ratti C., 2009. Eigenplaces: Analyzing cities using the space-time structure of the mobile phone network. Environment and Planning, B, 36: 824-836.

Reades J., Calabrese F., Sevtsuk A. \& Ratti C., 2007. Cellular census: Explorations in urban data collection. IEEE Pervasive Computing, 6(3): 30-38.

Reggiani A. \& Nijkamp P. (eds), 2009. Complexity and spatial networks. Springer-Verlag, Berlin.
Reggiani A. \& NiJKAmp P., 2010. Connectivity and concentration in airline networks. European Journal of Information Systems, March: 1-13.

Rozenblat C. \& Melançon G., 2009. A small world perspective on urban systems. In: Bavaud F. \& Mager C. (eds), Handbook of theoretical and quantitative geography. UNIL, Lausanne: 431-457.

SAFARZYNSKA K., 2010. Evolutionary modelling of transitions to sustainable development. PhD thesis, VU University, Amsterdam.

Shiode N., Li C., Batty M., Longley P. \& Maguire D., 2002. Digital cities: Impacts and penetration of location- based services. University College, London. UCL Working Papers.

SIMON H., 1962. The architecture of complexity. Proceedings of the American Philosophical Society, 106(6): 467-482.

STAм E., 2006. A process model of locational change: implications for an evolutionary economic geography. In: Pyka A. \& Hanusch H. (eds), Applied evolutionary economics and the knowledge-based economy. Edward Elgar, Cheltenham: 143-165.

Steenbruggen J., Borzacchiello M.T., Nijkamp P. \& Scholten H., 2010. Real-time data from mobile phone networks for traffic management. Research memorandum 2010-3. Dept. of Spatial Economics, VU University, Amsterdam.

STORPER M., 1997. The regional world. Territorial development in a global economy. Guilford Press, London.

SuI D.Z., 2004. GIS, Cartography and the 'Third Culture': Geographic imaginations in the computer age. The Professional Geographer, 56(1): 62-72.

ToBlen W., 1970. A computer movie simulating urban growth in the Detroit region. Economic Geography, 46(2): 234-240.

TOBLER W., 2004. On the first law of geography: A reply. Annals of the Association of American Geographers, 94(2): 304-310.

TRANOS E., 2010. The geography of the Internet infrastructure in Europe. PhD thesis, Newcastle University, Newcastle.

WARF B. (ed.), 2006. Encyclopedia of human geography. Sage, Thousand Oaks, CA.

WatTs D.J. \& Strogatz S.H., 1998. Collective dynamics of 'small-world' networks. Nature, 393: 440-442.

WiLson A.G., 2009. The thermodynamics of the city. In: Reggiani A. \& Nijkamp P. (eds), Complexity and spatial networks. Springer-Verlag, Berlin: 11-31.

YU H. \& SHAW S., 2008. Exploring potential human activities in physical and virtual spaces: A spatio-temporal GIS approach. International Journal of Geographical Information Science, 22(4): 409-430. 